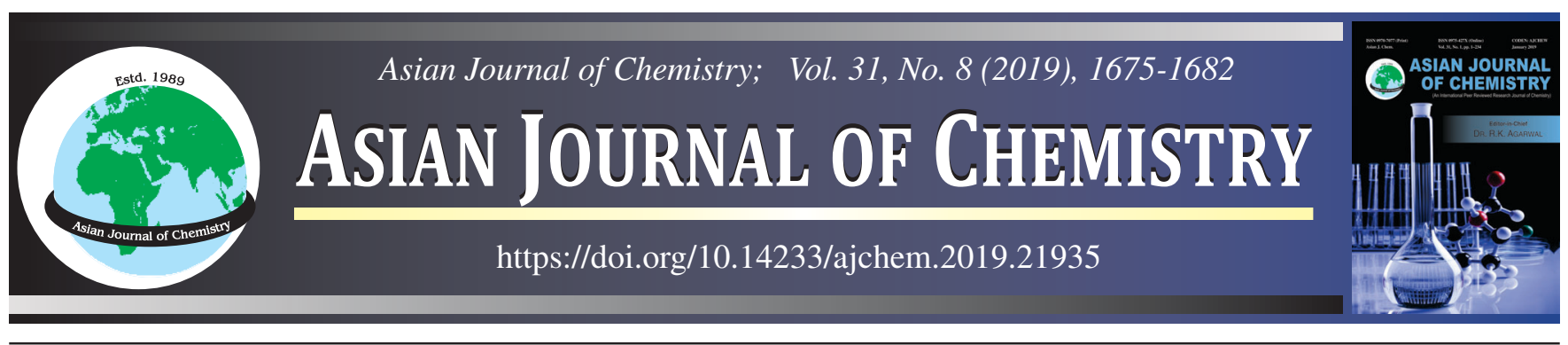

\title{
Enhanced Adsorption of Methylene Blue and Congo Red from Aqueous Solutions by MCM-41/HKUST-1 Composites
}

\author{
D.O. Sulistiono, E. SAntoso and R. Ediati*
}

Department of Chemistry, Institut Teknologi Sepuluh Nopember, Surabaya, Indonesia

*Corresponding author: Fax: +62 315928314; Tel: +62 315943353; E-mail: ratna.ediati@gmail.com; detysulistiono@gmail.com; eko.es39@gmail.com

\begin{abstract}
Impregnation of mesoporous silica MCM-41 on metal organic framework type HKUST-1 or often called CuBTC $($ BTC $=1,3,5$ benzenetricarboxylate) has been successfully carried out by solvothermal methods in a solvent mixture of water, ethanol and $N, N$ dimethylformamide (DMF). The XRD patterns of the obtained solids showed that MCM-41/HKUST-1 composites had the same crystalline phase as pure as HKUST-1. SEM images revealed that the impregnation of the mesoporous silica to HKUST-1 did not alter the surface morphology of the original HKUST-1, which had octahedral shapes. In addition, the thermal stability of the MCM-41/HKUST-1 composites reached $302{ }^{\circ} \mathrm{C}$, increased by $292^{\circ} \mathrm{C}$ in comparison to the HKUST-1, even though the impregnation process resulted in a decreased in the specific surface area of the composites. Furthermore, MCM-41/HKUST-1 composites showed outstanding performance as adsorbent of methylene blue and Congo red in aqueous solutions. Results of adsorption studies showed that a pseudo-second order kinetics and Langmuir isotherm were observed for both types of dyes.
\end{abstract}

Keywords: Methylene blue, Congo red, HKUST-1, MCM-41, Composite, Adsorbent, Adsorption capacity.

\section{INTRODUCTION}

The presence of dyes in the environment is not only disturbing the ecosystem balance, but most of the dyes are also toxic [1]. The textile industry is one of the industries that produces large amounts of dyestuff waste. Some type of dyes that are often use in textile industries are azo dyes, such as methylene blue (MB) and Congo red (CR) which can cause adverse effects not only for the environment but also for humans and animals $[2,3]$. Several chemical, physical and biological treatment (e.g., adsorption [4], coagulation-flocculation [5], photocatalytic degradation [6], membrane filtration [7] and electrochemical methods [8]) have been applied to remove dye molecules from wastewaters. Among them, adsorption method is the most simple and effective method, therefore, it is widely used for removal of dyes. Activated carbon is one of the most common types of adsorbent used in dye adsorption applications, but it is difficult to regenerate and expensive in manufacturing processes [9].

Metal organic framework (MOF) is an inorganic compound composed of clusters of metal ions that form coordination bond with organic molecules into one, two or three dimensions structures. Metal organic framework is formed by the coordination bond between metal ions or clusters as the central atom and the organic ligand as a linker [10]. Metal ions or clusters and organic ligands in the formation of metal organic framework have a very important role, because when the type of metal and ligands are changed it will form a new sub-class metal organic framework [11]. Because of various combinations of metals and ligands, this can make the pore size and specific surface area of the metal organic framework vary with certain characteristics. So a few metal organic framework is applied as gas storage [12], catalyst [13], adsorption of heavy metals and organic contaminant [14] and drug delivery [15].

One of the sub-classes of metal organic framework is $\mathrm{Cu}-\mathrm{BTC}\left[\mathrm{Cu}_{3}(\mathrm{BTC})_{2}, \mathrm{BTC}=1,3,5\right.$-benzenetricarboxylate $]$ also known as HKUST-1. Some previous studies have reported that metal organic framework type HKUST-1 is widely used in the adsorption process because it has a regular pore size and larger specific surface area, but some problems appears when the micro pore size of metal organic framework block the molecular diffusion process $[16,17]$. Therefore, combining metal

This is an open access journal, and articles are distributed under the terms of the Attribution 4.0 International (CC BY 4.0) License. This license lets others distribute, remix, tweak, and build upon your work, even commercially, as long as they credit the author for the original creation. You must give appropriate credit, provide a link to the license, and indicate if changes were made. 
organic framework with a variety of functional material to form metal organic framework composites which improve its performance in application process. Kondo et al. [16] reported that composite performance of HKUST-1-SBA-15 showed better result in ethanol adsorption compared to pure HKUST1, Tari et al. [18] showed that MCM-41/Cu (BDC) composites in $\mathrm{CO}_{2}$ adsorption have a higher adsorption capacity compared to pure HKUST-1.

In present study, mesoporous silica MCM-41 with regular pore size and large specific surface area was added into the reaction mixture of HKUST-1. The performance of obtained MCM-41/HKUST-1 composites was evaluated as adsorbent for methylene blue and Congo red in aqueous solutions, including adsorption kinetics and isotherms.

\section{EXPERIMENTAL}

Copper(II) nitrate trihydrate $\left[\mathrm{Cu}\left(\mathrm{NO}_{3}\right)_{2} \cdot 3 \mathrm{H}_{2} \mathrm{O}, 99 \%\right]$ and benzene-1,3,5-tricarboxylic acid $\left(\mathrm{H}_{3} \mathrm{BTC}, 98 \%\right)$ were purchased from Sigma Aldrich, ethanol (EtOH, $99.8 \%$ ), methanol (MeOH, $99.8 \%$ ) and $N, N^{\prime}$-dimethylformamide (DMF, 99.88 $\%$ ) were purchased from Merck, MCM-41 was synthesized following the method reported by Badamali et al. [19]. Dyes simulation were made from methylene blue $\left(\mathrm{C}_{16} \mathrm{H}_{18} \mathrm{~N}_{3} \mathrm{SCl}, 99.8\right.$ $\%)$ and Congo red $\left(\mathrm{C}_{32} \mathrm{H}_{22} \mathrm{~N}_{6} \mathrm{Na}_{2} \mathrm{O}_{6} \mathrm{~S}_{2}, 99.8 \%\right)$ were obtained from Merck.

Synthesis of HKUST-1 and MCM-41/HKUST-1 composites: The synthesis procedure of HKUST-1 using solvothermal method was based on the study reported by Chowdhury et al. [20]. MCM-41/HKUST-1 composites were synthesized by dissolving a certain amount of $\mathrm{H}_{3} \mathrm{BTC}(0.67 \mathrm{~g}, 3 \mathrm{mmol})$ in 20 $\mathrm{mL}$ of 50:50 vol \% solvent mixture of ethanol and DMF. Then, the mesoporous silica MCM-41 as support was added into the $\mathrm{H}_{3}$ BTC solution with a variation of $3.5 ; 7$ and $14 \%$ to the weight of HKUST-1. In different batch, $\mathrm{Cu}\left(\mathrm{NO}_{3}\right)_{2} \cdot 3 \mathrm{H}_{2} \mathrm{O}(1.39$ $\mathrm{g}, 6 \mathrm{mmol}$ ) was dissolved in $10 \mathrm{~mL}$ deionized water. After that both of solutions were stirred for 15 min until homogeneous solution was obtained. The blue solution obtained was heated to $100{ }^{\circ} \mathrm{C}$ for the crystallization to occur. After the hydrothermal step, the reaction mixture was cooled to room temperature for $48 \mathrm{~h}$ forming a blue crystalline powder. Finally, the material obtained was washed with $40 \mathrm{~mL}$ DMF, followed by $60 \mathrm{~mL}$ methanol as many as three times in oil bath at temperature ranging from $40^{\circ} \mathrm{C}$ until $55^{\circ} \mathrm{C}$. The synthesized materials have been denoted as MC (x)/HKUST-1, where $\mathrm{x}$ is the amount of addition mesoporous silica MCM-41.

Characterization of HKUST-1 and MCM-41/HKUST1 composites: The crystal structure of synthesized materials were characterized by X-ray diffraction (XRD). The light source that used for the measurement was $\mathrm{Cu} \mathrm{K} \alpha$ radiation $(\lambda=1.5406$ $\AA$ ), with an acceleration of voltage and current of $40 \mathrm{kV}$ and $30 \mathrm{~mA}$, respectively. The analysis was carried out at an angle of $2 \theta$ from $3-50^{\circ}$ with a scanning interval of $0.017^{\circ} / \mathrm{s}$. The Fourier transform infrared (FT-IR) spectra was detected on a Shimadzu FTIR-8400S spectrometer with KBr pellets at wave numbers from 400 to $4000 \mathrm{~cm}^{-1}$. The morphologies of the synthesized materials were characterized by scanning electron microscopy (SEM) image and energy dispersive X-ray (EDX) data was obtained using EDAX advanced microanalysis at an accelerating voltage of $20 \mathrm{kV}$. TEM images were obtained using a JEOL JEM-1400 electron microscope at an accelerating voltage of $200 \mathrm{kV}$. The nitrogen adsorption-desorption isotherm was measured at $77 \mathrm{~K}$ on a Quantachrome Nova WinGas Sorption Instrument. The specific surface area and pore volume were measure using BET and BJH equation. Prior to measurement of $\mathrm{N}_{2}$ analysis, all samples were degassed under vacuum at $423 \mathrm{~K}$ for about overnight. Thermogravimetic curve were recorded on a Perkin Elmer Pyris 1 analyzer and analysis was carried out in the temperature range of 30 to $700{ }^{\circ} \mathrm{C}$ under air flow with a temperature rate of $10^{\circ} \mathrm{C} / \mathrm{min}$. The concentration solution after adsorption was analyzed using spectrophotometer UV-visible at wavelengths of $498 \mathrm{~nm}$ for Congo red and 664 $\mathrm{nm}$ for methylene blue.

Adsorption: Prior to the adsorption process, all adsorbents (HKUST-1, MC(7)/HKUST-1 and MC(14)/HKUST-1) were degassed at $120^{\circ} \mathrm{C}$ for $24 \mathrm{~h}$ under the nitrogen atmosphere to remove impurities. Adsorbent ( $10 \mathrm{mg}$ ) was added to the aqueous solution of methylene blue or Congo red $(20 \mathrm{~mL})$ with the different concentrations. The mixture was stirred for a fixed time (3-21 $\mathrm{min}$ ) at $303 \mathrm{~K}$. After the adsorption process within a predetermined time, the solution was centrifuged at a rate of $3500 \mathrm{rpm}$ for $10 \mathrm{~min}$ to separate the adsorbent with adsorbate. Then the concentration of solution was measured using a UVvisible spectrophotometer at the calibrated maximum wavelength. Adsorption capacity and removal \% of dyes adsorption can be calculated using the formula:

$$
\begin{gathered}
\mathrm{Q}_{\mathrm{e}}=\frac{\left(\mathrm{C}_{\mathrm{o}}-\mathrm{C}_{\mathrm{e}}\right) \times \mathrm{V}}{\mathrm{W}} \\
\operatorname{Removal}(\%)=\frac{\mathrm{C}_{\mathrm{o}}-\mathrm{C}_{\mathrm{e}}}{\mathrm{C}_{\mathrm{o}}} \times 100
\end{gathered}
$$

where $\mathrm{C}_{\mathrm{o}}$ and $\mathrm{C}_{\mathrm{e}}$ were initial and equilibrium concentrations in $\mathrm{mg} / \mathrm{L}, \mathrm{W}$ was the mass of adsorbent $(\mathrm{g}$ ) and $\mathrm{V}$ was the volume of solution (L).

\section{RESULTS AND DISCUSSION}

X-ray diffraction (XRD) analysis: In this study, XRD patterns of the pure HKUST-1 and composites ware shown in Fig. 1. XRD diffractogram had a high intensity which showed that the synthesized materials had high crystallinity. The diffraction peaks of all the samples were similar to those reported $[4,20]$. In the $2 \theta$ range of $3^{\circ}$ to $50^{\circ}$, the dominant peaks of synthesized HKUST- 1 at $2 \theta=6.69^{\circ}, 2 \theta=9.46^{\circ}, 2 \theta$ $=11.6^{\circ}$ and $2 \theta=13.4$, with the index at each peak was $(200)$, (2 20 ), (2 22 2) and (4 0 0) [20]. All synthesized materials did not show impurities in the form of $\mathrm{CuO}$ and $\mathrm{Cu}_{2} \mathrm{O}$ which appeared at the peak $2 \theta$ around $35^{\circ}-36^{\circ}$ [21].

It can be seen in Fig. 1, XRD pattern of composites had the same pattern with the XRD pattern of pure HKUST-1. This indicated that the addition of MCM-41 did not affect the crystal structure formed [22], however the intensity of the composite decreased with the addition of MCM-41. This was possible because the amorphous MCM-41 structure may affect the crystallinity of HKUST-1 [23]. 


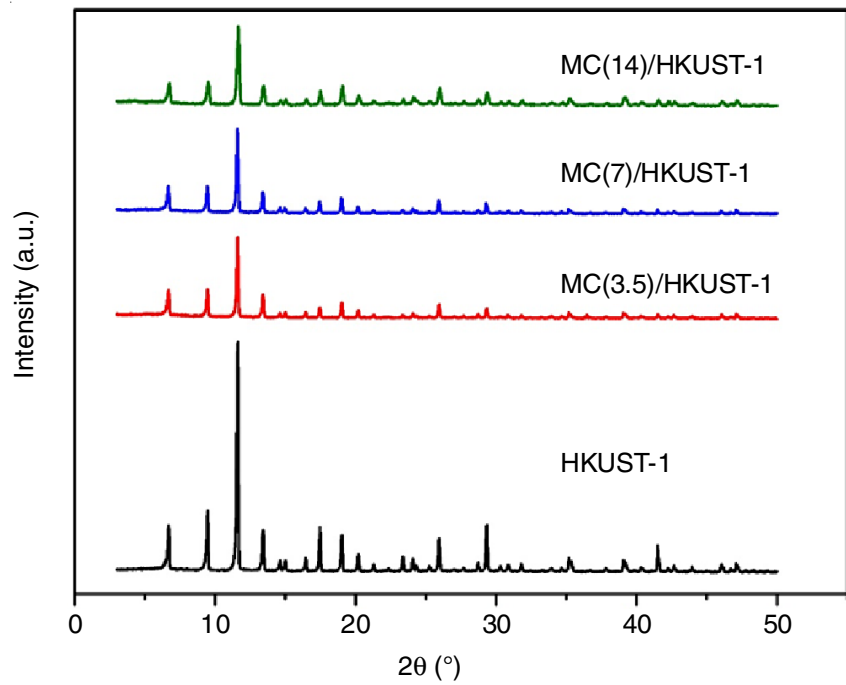

Fig. 1. XRD patterns of the pure HKUST-1 and MCM-41/HKUST-1 composites

Fourier transform infrared (FT-IR): The FT-IR spectra of synthesized materials is shown in Fig. 2. The absorption band around $727 \mathrm{~cm}^{-1}$ indicated stretching vibration of $\mathrm{Cu}-\mathrm{O}$, in which the oxygen atom in ligand BTC was coordinated with $\mathrm{Cu}$ [21]. Another typical absorption band from HKUST1 also appeared in regions 1640, 1447 and $1368 \mathrm{~cm}^{-1}$ which showed the stretching of the $\mathrm{C}-\mathrm{O}$ group, vibration of the $\mathrm{OH}$ group and stretching vibration of the $\mathrm{C}=\mathrm{O}$ group derived from the carboxylic group [23]. Water molecules bonding in HKUST1 was found in absorption peak around $3245 \mathrm{~cm}^{-1}$ [9]. Absence of specific absorption peaks at $615,610,500$ and $410 \mathrm{~cm}^{-1}$ indicated that synthesized materials ware free from impurities $\mathrm{CuO}$ and $\mathrm{Cu}_{2} \mathrm{O}$ crystals during nucleation of HKUST-1 [24]. As a comparison, characteristic spectra of MCM-41 was observed at $1094 \mathrm{~cm}^{-1}$ [25]. The MCM-41/HKUST-1 composites not only showed the typical adsorption band of HKUST-1, but also adsorption band from MCM-41, which indicated the successful loading of MCM-41 on HKUST-1.

Scanning electron microscopy (SEM): The typical morphology of pure HKUST-1 can be seen in Fig. 3a. The octahedral shape with shape edges of the Cu-BTC crystals was clearly seen in Fig. 3a. The morphology of synthesized material was consistent with other SEM images publication for this material, HKUST-1 $[9,20,26]$. The SEM image of composites (Fig. 3b, 3c) can be seen that after the addition of mesoporous silica

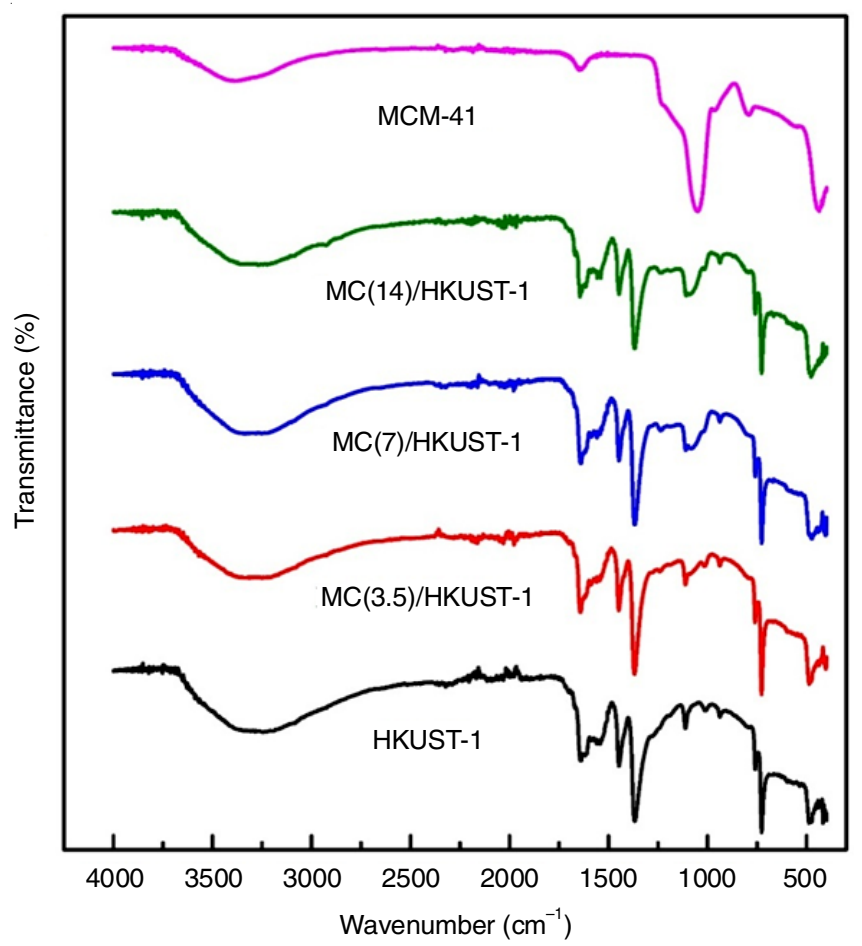

Fig. 2. FT-IR spectra of synthesized material

MCM-41, the surface morphology of crystals formed were irregular [27], however the resulting crystalline form still had the same morphology.

Transmission electron microscope (TEM): The morphology structures of pure HKUST- 1 and MC(14)/HKUST- 1 composites were further characterized by transmission electron microscope analysis. TEM image of pure HKUST-1 is shown in Fig. 4a, which indicates the presence of uniform nanoparticles pore. The TEM morphology of composite showed that HKUST- 1 crystals grew inside the pore channel of MCM-41 with a more irregular pore structure [28]. This was in accordance with the SEM and XRD analysis in the previous discussion. It is difficult to obtain high quality TEM morphologies for these materials, probably because the sample was sensitive to electron beams [22].

Adsorption-desorption nitrogen: Fig. 5 shows the $\mathrm{N}_{2}$ adsorption-desorption isotherm and pore distribution of pure HKUST-1 and MCM-41/HKUST-1 composites and Table-1 summarizes the textural properties of the synthesized material
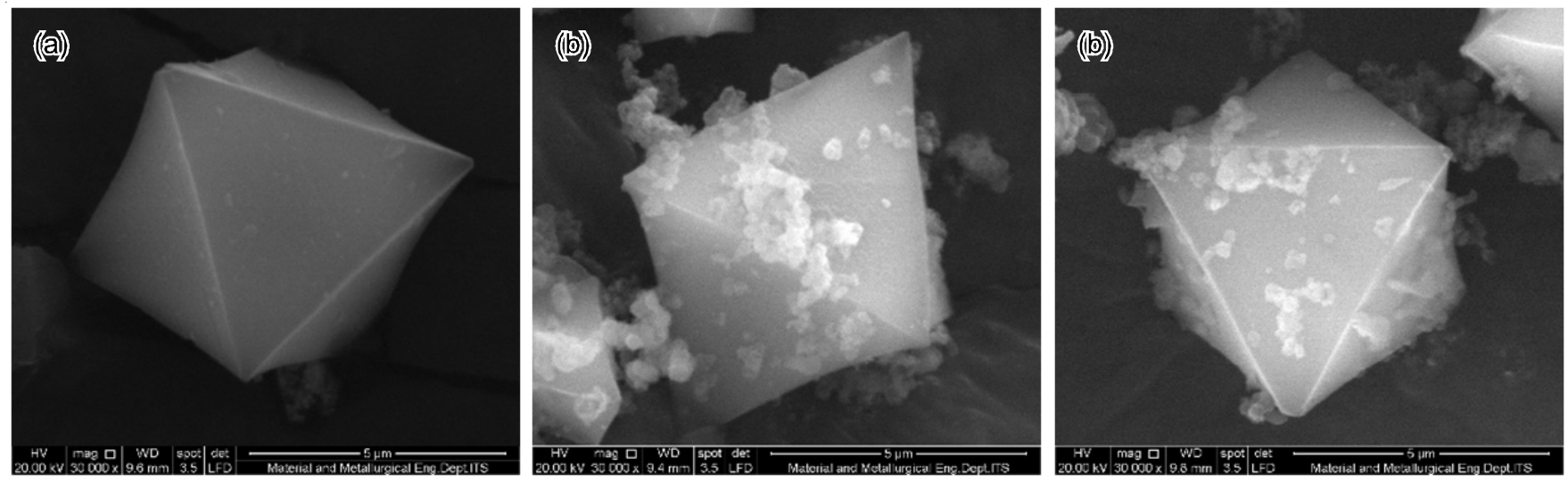

Fig. 3. SEM images of pure HKUST-1 (a) MC(7)/HKUST-1 (b) and MC(14)/HKUST-1 (c) 

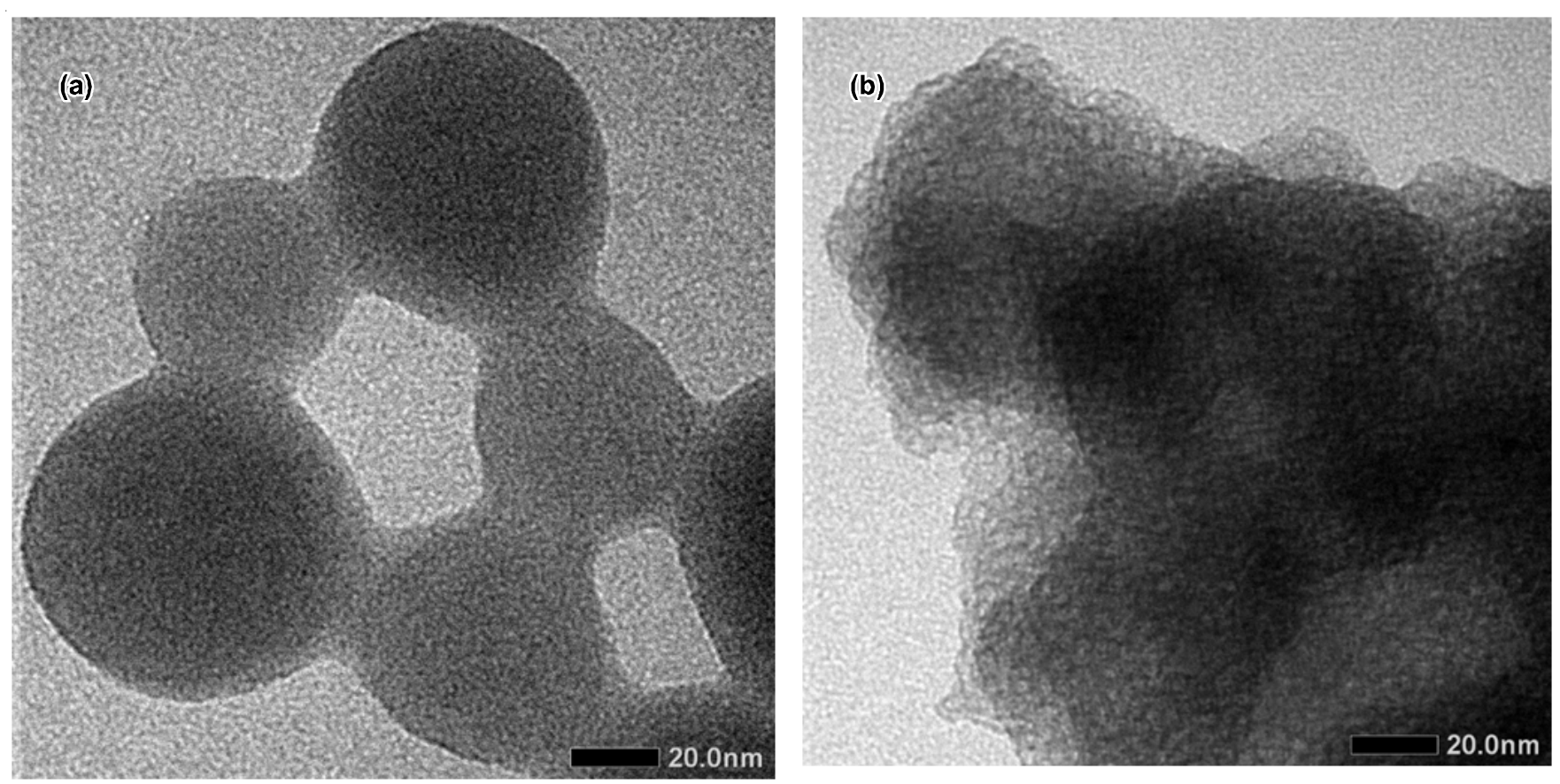

Fig. 4. TEM images of pure HKUST-1 (a) and MC(14)/HKUST-1 (b)
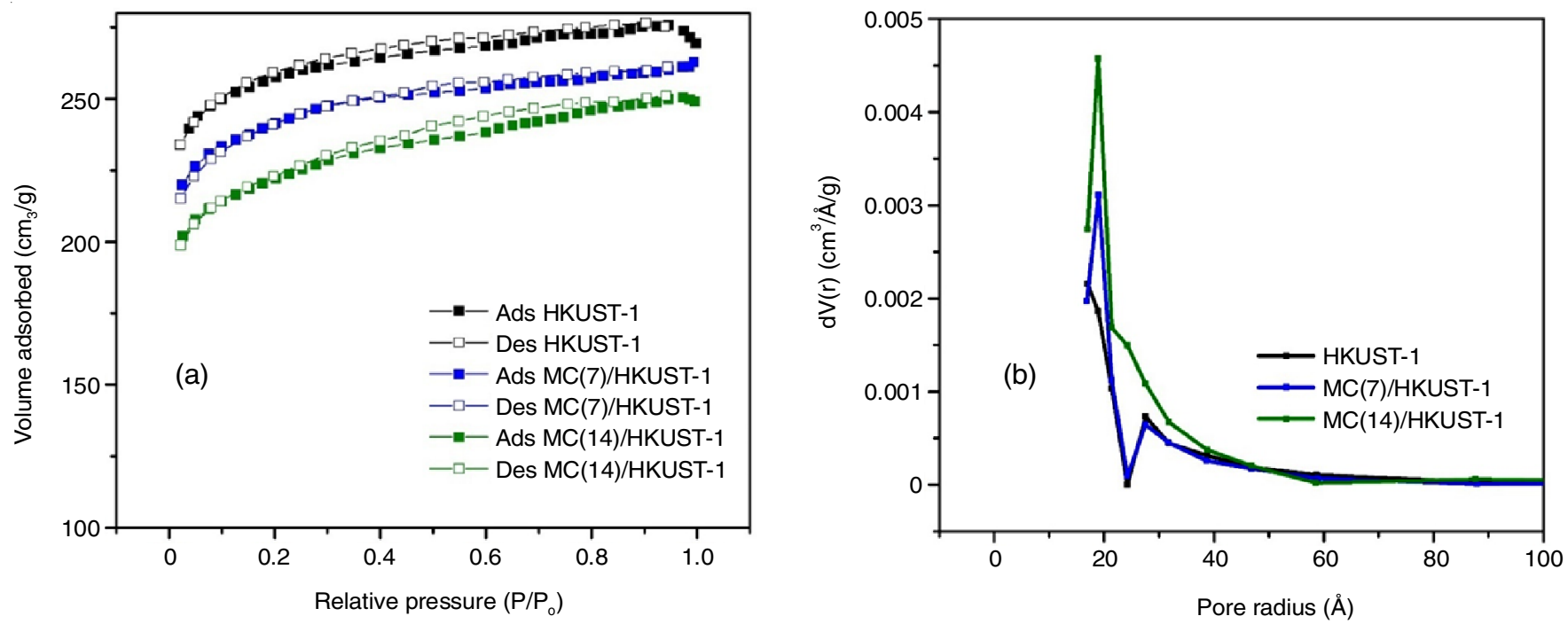

Fig. 5. $\mathrm{N}_{2}$ adsorption-desorption isotherm (a) and pore distribution (b) of pure HKUST-1 and MCM-41/HKUST-1 composites

TABLE-1

TEXTURAL PROPERTIES OF THE SYNTHESIZED MATERIAL AT DIFFERENT ADDITION OF MCM-41

\begin{tabular}{ccccc}
\hline Materials & $\mathrm{S}_{\mathrm{BET}}^{\mathrm{a}}\left(\mathrm{m}^{2} / \mathrm{g}\right)$ & $\mathrm{V}_{\text {meso }}\left(\mathrm{cm}^{3} / \mathrm{g}\right)$ & $\mathrm{V}_{\text {micro }}{ }^{\mathrm{c}}\left(\mathrm{cm}^{3} / \mathrm{g}\right)$ & 0.33 \\
MCM-41 & 887.5 & 0.33 & 0.31 & 3.81 \\
HKUST-1 & 784.1 & 0.09 & 0.31 & 2.12 \\
MC(7)/HKUST-1 & 734.7 & 0.12 & 0.28 & 2.18 \\
MC(14)/HKUST-1 & 686.1 & 0.12 & 0.25 & 2.24 \\
\hline
\end{tabular}

${ }^{a}$ BET surface area; ${ }^{b}$ Mesopore volume calculated using BJH method; ${ }^{\mathrm{c}}$ Micropore volume calculated using t-plot method; ${ }^{\mathrm{d}}$ Average pore diameter

at different addition of MCM-41. The isotherm of pure HKUST1 showed type I according to the IUPAC classification, which is characteristic of microporous materials [22]. The result of MCM-41/HKUST-1 composites had the same type isotherm with pure HKUST-1. The BET surface area of synthesis materials measured from the nitrogen isotherm was $784.1 \mathrm{~m}^{2} / \mathrm{g}$ for pure HKUST-1, was higher than composites, 734.7 and 686.1 for MC(7)/HKUST-1 and MC(14)/HKUST-1, respectively. Addi- tion of mesoporous silica MCM-41 can decrease the surface area of composite, this was possible because blockage of the HKUST-1 pore aperture by mesoporous silica MCM-41. However, composites produced a larger volume pore than pure HKUST-1. This was consistent with the result of previous research [22].

Thermal gravimetric analysis: The thermal gravimetric analysis of pure HKUST-1 is shown in Fig. 6a, with some 
step weight loss of the adsorbent when heated up to $700{ }^{\circ} \mathrm{C}$ under the air atmosphere. The first main weight-loss step up to $150{ }^{\circ} \mathrm{C}$ was due to the dehydration of the material [29]. The next step occurred $36 \%$ weight loss in the temperature range of $292{ }^{\circ} \mathrm{C}$ which showed the decomposition of the BTC organic ligand which caused a change in the structure of HKUST-1 and changed in the form of its metal oxide, $\mathrm{CuO}$ [29]. The result of MCM-41/HKUST-1 composites (Fig. 6b) had the same step as pure HKUST-1, but MC(14)/HKUST-1 composite had higher thermal stability value than pure HKUST-1 of $302{ }^{\circ} \mathrm{C}$. After the loading MCM-41 on HKUST-1, the thermal stability of composite increased remarkably may be due to the formation of the hydrogen bonds [17].

\section{Dye adsorption (Congo red and methylene blue)}

Effect of contact time: The adsorption capacity in variation the contact time is shown in Fig. 7. It was observed that the adsorption capacity had increased with longer adsorption time and reached saturation state after $15 \mathrm{~min}$. This may be explained that the dye molecules were adsorbed quickly on the outer surface when there was much more available vacant surface site in adsorbent during the initial stage and then reached saturated state at $t$ time [30]. Fig. 7 shows the relation-

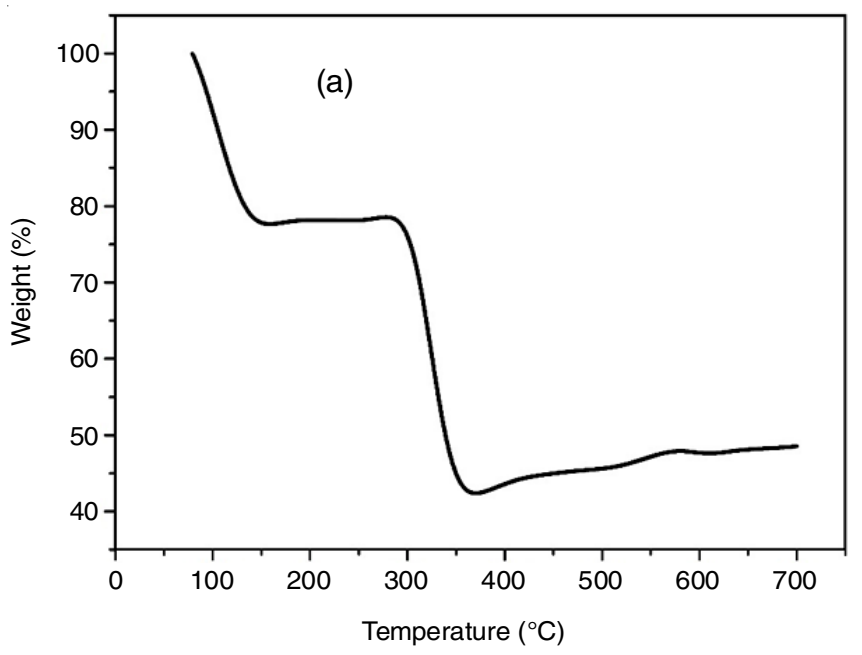

ship between contact time and the amount of dye adsorbed on the solid phase.

Effect of initial concentration: The initial concentration of the adsorbate was one of the important aspects in the adsorption process. The adsorption behaviours of pure HKUST-1 and MCM-41/HKUST-1 composites towards methylene blue and Congo red with differential initial concentrations were compared as shown in Fig. 8. It can be seen that adsorption capacity of Congo red is higher than that of methylene blue. This was possible because of differences in molecular size and functional groups that were bound to two types of adsorbates [31]. The pore structure of MCM-41/HKUST-1 composites was larger than that of pure HKUST-1 due to modification of MCM-41, resulting in favourable adsorption performance with more active sites [32].

Kinetic analysis: Adsorption kinetics from both adsorbates (methylene blue and Congo red) were examined in terms of pseudo first-order and pseudo second-order kinetics equation as follows [33]:

$$
\begin{gathered}
\ln \left(\mathrm{Q}_{\mathrm{e}}-\mathrm{Q}_{\mathrm{t}}\right)=\ln \mathrm{Q}_{\mathrm{e}}-\mathrm{K}_{1} \mathrm{t} \\
\frac{1}{\mathrm{Q}_{\mathrm{t}}}=\frac{1}{\mathrm{~K}_{2} \mathrm{Q}_{\mathrm{e}}^{2}}+\frac{\mathrm{t}}{\mathrm{Q}_{\mathrm{e}}}
\end{gathered}
$$

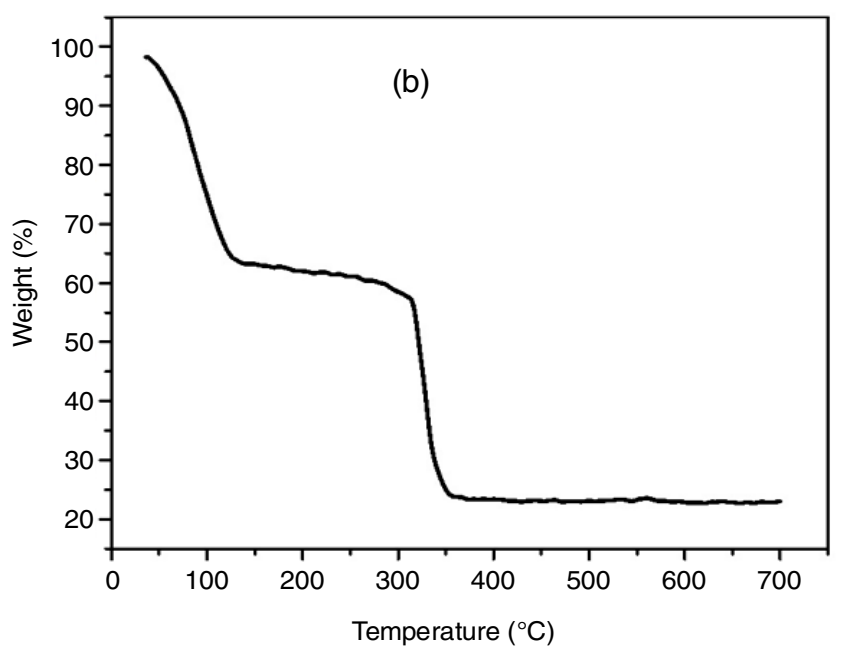

Fig. 6. Thermogravimetric analysis of pure HKUST-1 (a) and MC(14)/HKUST-1 (b)
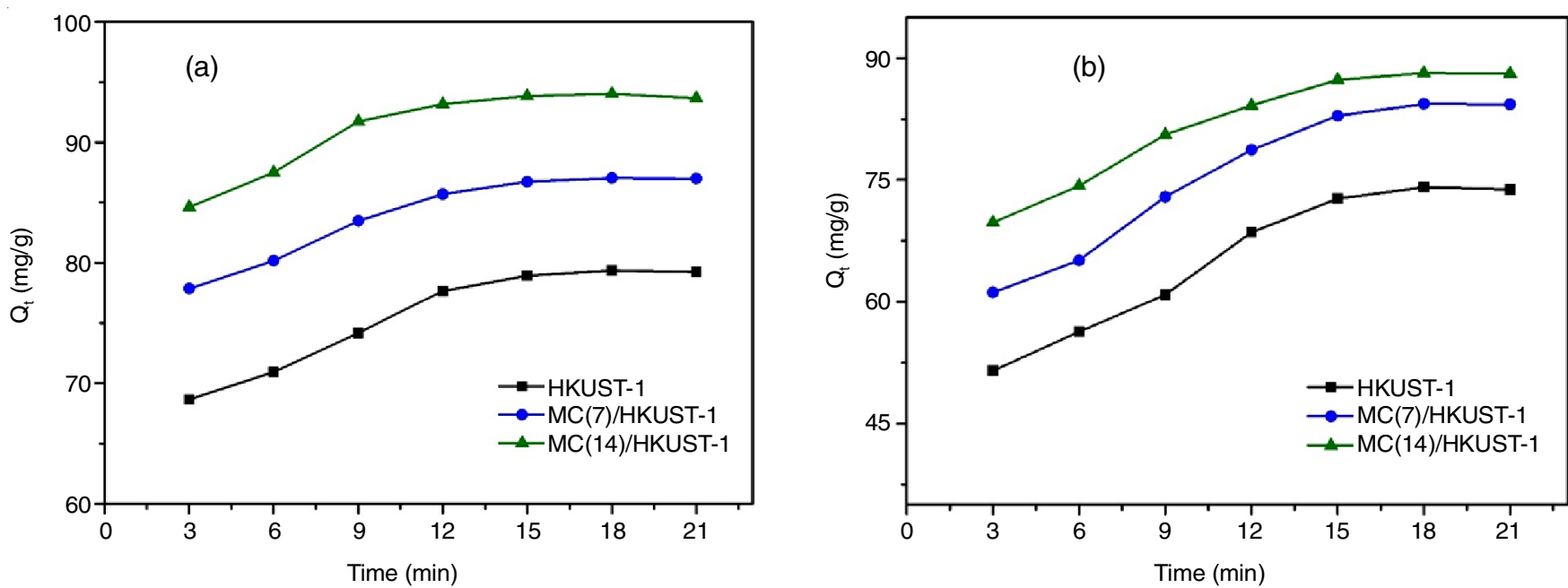

Fig. 7. Effect of contact time on uptake of methylene blue (a) and congo red (b) on materials synthesized 

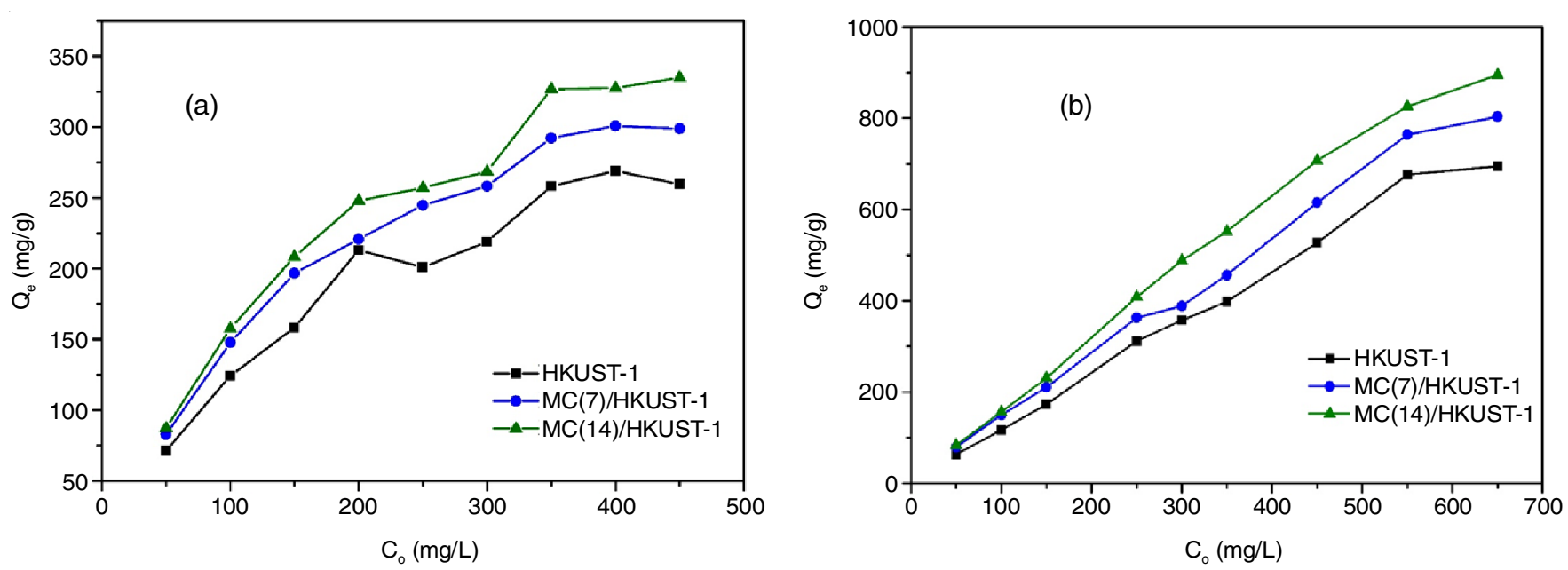

Fig. 8. Effect of initial concentrations of methylene blue (a) and congo red (b)

where $\mathrm{Q}_{\mathrm{e}}$ and $\mathrm{Q}_{\mathrm{t}}$ were the adsorption capacity of methylene blue or Congo red onto adsorbent at equilibrium and at ' $\mathrm{t}$ ' time ( $\mathrm{min}$ ), respectively. The rate constant $\mathrm{k}_{1}$ and $\mathrm{k}_{2}$ value was calculated from the slope of the plots of $\ln \left(\mathrm{Q}_{\mathrm{e}}-\mathrm{Q}_{\mathrm{t}}\right)$ versus $\mathrm{t}$ (Fig. 9) and plot of t/Qt versus t (Fig. 10), respectively. The kinetic adsorption of both were given in Table-2.

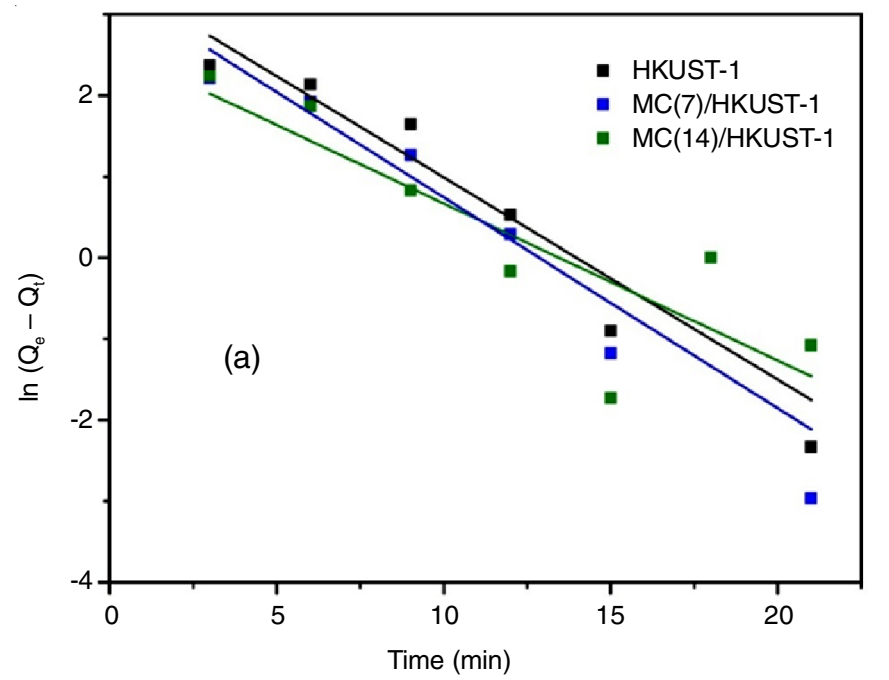

There was a significant difference in the value of experimental and calculation adsorption capacity when using pseudo first-order kinetic studies.However, a pseudo secondorder kinetics plot showed the suitability of the values between the two data of $\mathrm{Q}_{\mathrm{e}}\left(\mathrm{R}^{2}\right.$ value/above 0.99$)$. This suggested that the adsorption process on both types of adsorbates using

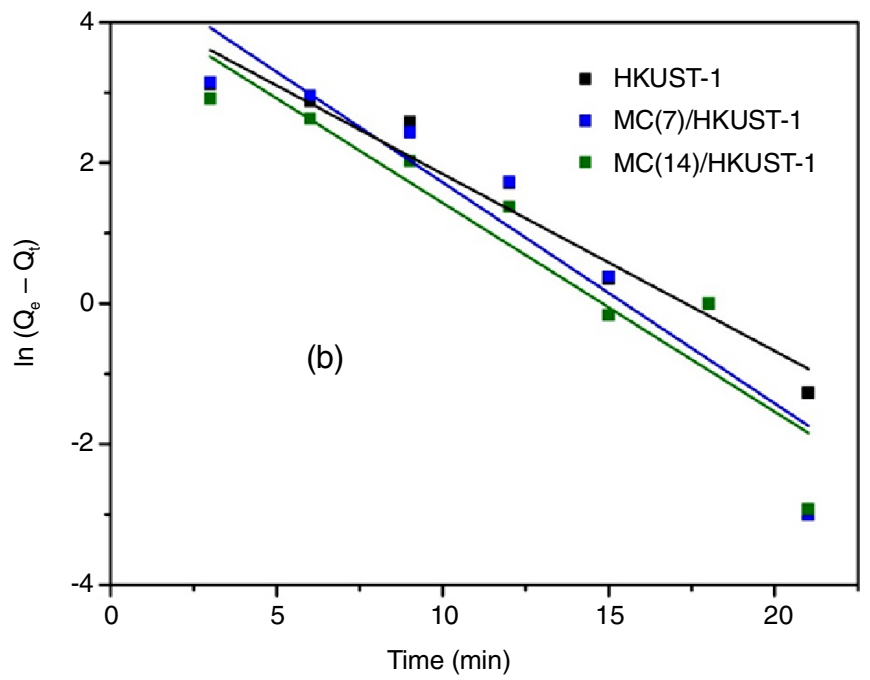

Fig. 9. Plots of pseudo first-order kinetics for the adsorption of methylene blue (a) and congo red (b)
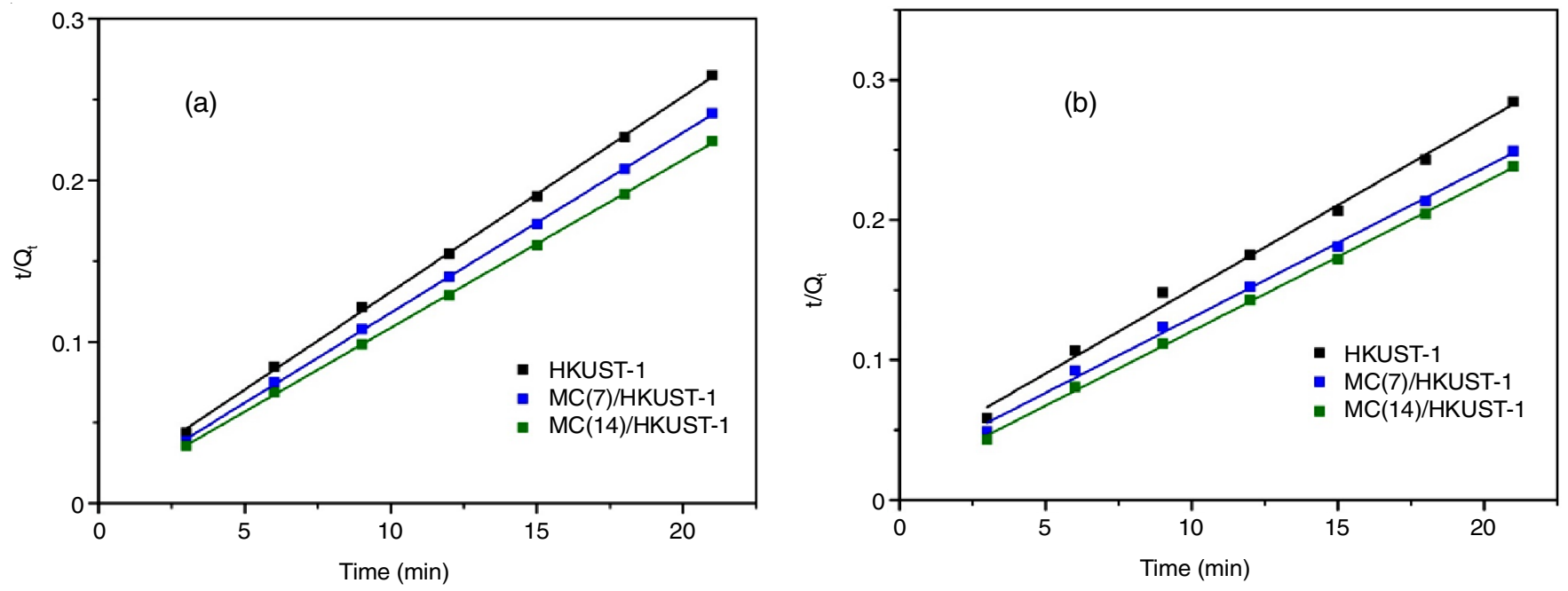

Fig. 10. Plots of pseudo second-order kinetics for the adsorption of methylene blue (a) and congo red (b) 


\begin{tabular}{|c|c|c|c|c|c|c|c|}
\hline \multicolumn{8}{|c|}{$\begin{array}{c}\text { TABLE-2 } \\
\text { KINETIC PARAMETERS AND CORRELATION COEFFICIENTS FOR THE PSEUDO } \\
\text { FIRST-ORDER EQUATION AND SECOND-ORDER EQUATION }\end{array}$} \\
\hline \multirow{2}{*}{ Materials } & \multirow{2}{*}{ Dye } & \multicolumn{3}{|c|}{ Pseudo first-order } & \multicolumn{3}{|c|}{ Pseudo second-order } \\
\hline & & $\mathrm{R}^{2}$ & $\mathrm{Qe}_{\mathrm{cal}}$ & $\mathrm{K}_{1}$ & $\mathrm{R}^{2}$ & $\mathrm{Qe}_{\mathrm{cal}}$ & $\mathrm{K}_{2}$ \\
\hline HKUST-1 & & 0.951 & 1.47 & 0.22 & 0.983 & 83.33 & 0.004 \\
\hline MC(7)/HKUST-1 & Congo red & 0.878 & 1.58 & 0.31 & 0.996 & 93.45 & 0.005 \\
\hline MC(14)/HKUST-1 & & 0.887 & 1.48 & 0.29 & 0.999 & 94.33 & 0.007 \\
\hline HKUST-1 & & 0.882 & 1.24 & 0.24 & 0.999 & 82.64 & 0.014 \\
\hline MC(7)/HKUST-1 & $\begin{array}{l}\text { Methylene } \\
\text { blue }\end{array}$ & 0.845 & 1.26 & 0.26 & 0.999 & 89.28 & 0.019 \\
\hline MC(14)/HKUST-1 & & 0.735 & 0.95 & 0.19 & 0.999 & 96.15 & 0.023 \\
\hline
\end{tabular}

HKUST-1 and MCM-41/HKUST-1 composites occurs chemically [9].

Adsorption isotherms: The study of adsorption isotherms illustrated how the adsorbent interacts with the adsorbate in a state of equilibrium. The equilibrium data of adsorbent was then fitted to the Langmuir and Freundlich isotherm models [31]. In this work, both models were presented in equation:

$$
\begin{gathered}
\frac{1}{Q_{e}}=\frac{1}{Q_{m}}+\frac{1}{Q_{m} \times K_{L} \times C_{e}} \\
\ln Q_{e}=\ln \mathrm{K}_{F}+\frac{1}{n} \ln C_{e}
\end{gathered}
$$

where $\mathrm{C}_{\mathrm{e}}(\mathrm{mg} / \mathrm{L})$ was the equilibrium concentration of adsorbate $(\mathrm{mg} / \mathrm{L})$ and $\mathrm{Q}_{\mathrm{m}}$ was the maximum adsorption capacity $(\mathrm{mg} /$ g). $\mathrm{K}_{\mathrm{L}}$ and $\mathrm{K}_{\mathrm{F}}$ were Langmuir and Freundlich constant which can be determined from the slope and intercept. The calculated constants according to the two isotherm equations with standard deviation $\left(\mathrm{R}^{2}\right)$ were presented in Table-3. It can be seen that the adsorption fits Langmuir model (Fig. 11) better than
Freundlich model (Fig. 12) for methylene blue and Congo red adsorption onto pure HKUST-1 and MCM-41/HKUST-1 composites because all the coefficients $\mathrm{R}^{2}$ value of the Langmuir equations obtained were higher than Freundlich model. This indicated that adsorption occurs on a monolayer on a homogeneous surface and chemical interactions occur between the adsorbent and the adsorbate [9].

\section{Conclusion}

In this work, HKUST-1 and MCM-41/HKUST-1 composites were introduced for the adsorptive removal of methylene blue and Congo red. All the synthesized materials had regular octahedral morphology and high porosity. The results of adsorption study showed that the addition of mesoporous silica MCM-41 during the synthesis of HKUST-1 resulted in the increase in adsorption performance of the obtained MCM-41/ HKUST-1 composites on methylene blue and Congo red. A prominent adsorption performance of the composites was demonstrated toward Congo red in aqueous solution. Of the three types of material, adsorption on both types of dye adsor-

TABLE-3

LANGMUIR AND FREUNDLICH ISOTHERM PARAMETERS FOR THE ADSORPTION OF METHYLENE BLUE AND CONGO RED

\begin{tabular}{lcccc|ccc}
\hline \multicolumn{1}{c}{ Materials } & \multirow{2}{*}{ Dye } & \multicolumn{3}{c|}{ Langmuir } & \multicolumn{3}{c}{ Freundlich } \\
\cline { 3 - 8 } & & $\mathrm{R}^{2}$ & $\mathrm{Q}_{\mathrm{m}}$ & $\mathrm{K}_{\mathrm{L}}$ & $\mathrm{R}^{2}$ & $\mathrm{~K}_{\mathrm{F}}$ & $1 / \mathrm{n}$ \\
\hline HKUST-1 & \multirow{2}{*}{ Congo red } & 0.986 & 833 & 0.004 & 0.983 & 0.36 & 0.91 \\
MC(7)/HKUST-1 & 0.981 & 909 & 0.009 & 0.979 & 0.99 & 0.75 \\
MC(14)/HKUST-1 & & 0.972 & 1111 & 0.009 & 0.960 & 1.00 & 0.81 \\
\hline HKUST-1 & \multirow{2}{*}{ Methylene } & 0.983 & 277 & 0.023 & 0.950 & 1.18 & 0.41 \\
MC(7)/HKUST-1 & \multirow{2}{*}{ blue } & 0.987 & 284 & 0.047 & 0.970 & 1.32 & 0.35 \\
MC(14)/HKUST-1 & & 0.978 & 312 & 0.035 & 0.967 & 1.37 & 0.33 \\
\hline
\end{tabular}
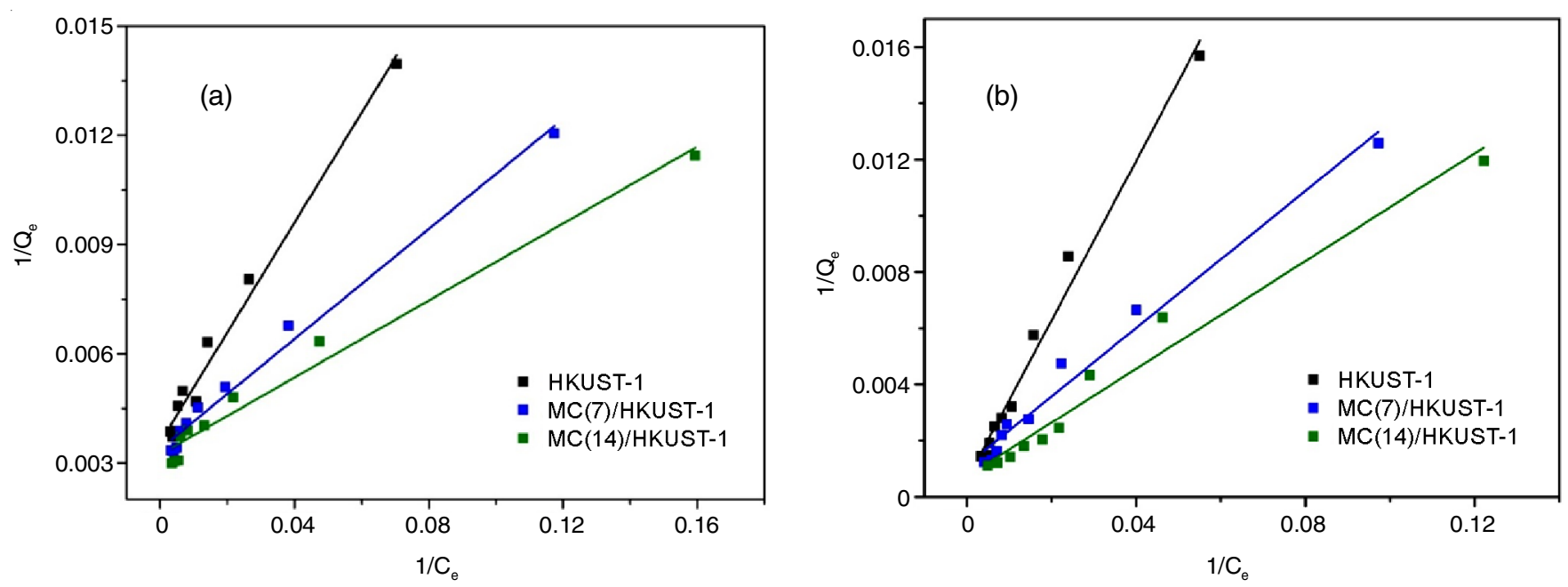

Fig. 11. Plots of Langmuir model for methylene blue (a) and congo red (b) adsorption 

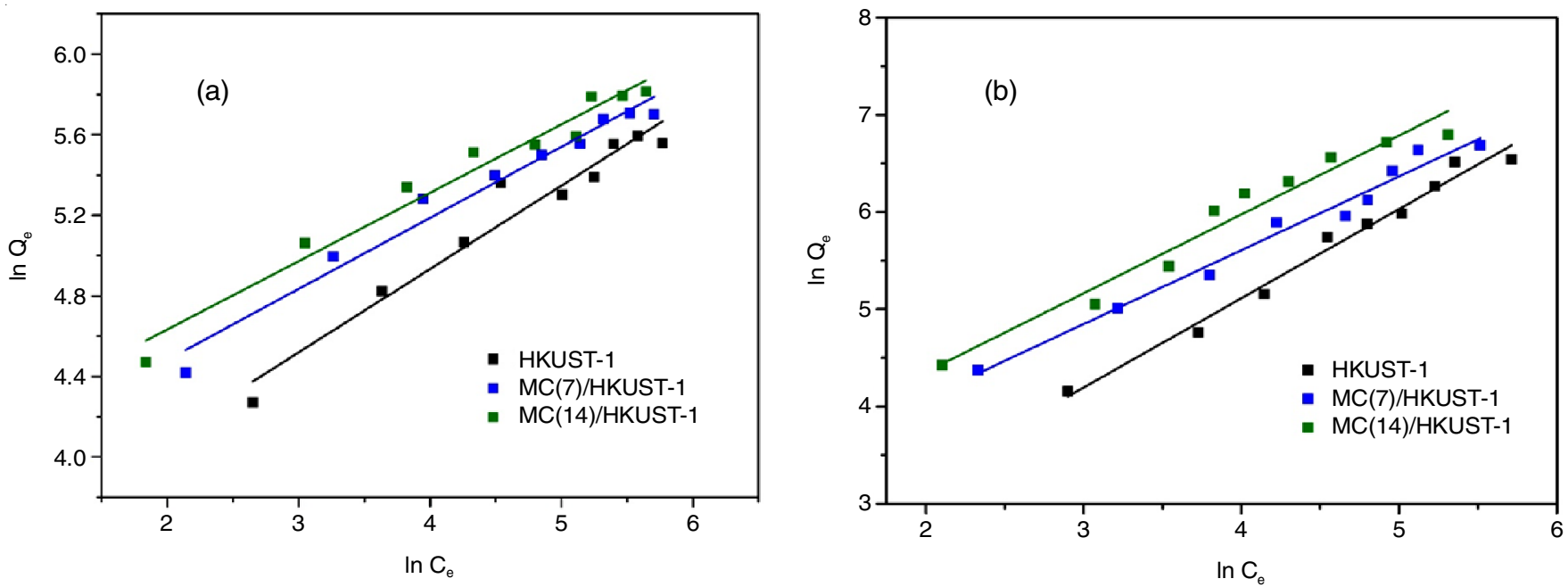

Fig. 12. Plots of Freundlich model for methylene blue (a) and congo red (b) adsorption

ption kinetics follows the pseudo second order and Langmuir model had a higher regression coefficient compared to Freundlich model.

\section{ACKNOWLEDGEMENTS}

The authors gratefully acknowledge the funding from Ministry of Research, Technology and Higher Education, Republic of Indonesia, through Competency Grants, Material Chemistry and Energy Laboratory, Department of Chemistry, as well as The Energy Laboratory of Institut Teknologi Sepuluh Nopember (ITS) Surabaya for facilities supporting this work.

\section{CONFLICT OF INTEREST}

The authors declare that there is no conflict of interests regarding the publication of this article.

\section{REFERENCES}

1. S. Chen, J. Zhang, C. Zhang, Q. Yue, Y. Li and C. Li, Desalination, 252, 149 (2010);

https://doi.org/10.1016/j.desal.2009.10.010.

2. B. Royer, N.F. Cardoso, E.C. Lima, J.C.P. Vaghetti, N.M. Simon, T. Calvete and R.C. Veses, J. Hazard. Mater., 164, 1213 (2009); https://doi.org/10.1016/j.jhazmat.2008.09.028.

3. S. Chatterjee, D.S. Lee, M.W. Lee and S.H. Woo, Bioresour. Technol., 100, 3862 (2009);

https://doi.org/10.1016/j.biortech.2009.03.023.

4. Z. Wang, J. Wang, M. Li, K. Sun and C.J. Liu, Sci. Rep., 4, 5939 (2014); https://doi.org/10.1038/srep05939.

5. Y.-Y. Lau, Y.-S. Wong, T.-T. Teng, N. Morad, M. Rafatullah and S.-A. Ong, RSC Adv., 5, 34206 (2015);

https://doi.org/10.1039/C5RA01346A.

6. A. Houas, H. Lachheb, M. Ksibi, E. Elaloui, C. Guillard and J.-M. Herrmann, Appl. Catal. B, 31, 145 (2001); https://doi.org/10.1016/S0926-3373(00)00276-9.

7. N. Zaghbani, A. Hafiane and M. Dhahbi, Sep. Purif. Technol., 55, 117 (2007);

https://doi.org/10.1016/j.seppur.2006.11.008.

8. M. Panizza, A. Barbucci, R. Ricotti and G. Cerisola, Sep. Purif. Technol., 54, 382 (2007); https://doi.org/10.1016/j.seppur.2006.10.010.

9. S. Lin, Z. Song, G. Che, A. Ren, P. Li, C. Liu and J. Zhang, Micropor. Mesopor. Mater., 193, 27 (2014); https://doi.org/10.1016/j.micromeso.2014.03.004.

10. Q.-L. Zhu and Q. Xu, Chem. Soc. Rev., 43, 5468 (2014); https://doi.org/10.1039/C3CS60472A

11. R.J. Kuppler, D.J. Timmons, Q.R. Fang, J.R. Li, T.A. Makal, M.D. Young, D. Yuan, D. Zhao, W. Zhuang and H.C. Zhou, Coord. Chem. Rev., 253, 3042 (2009); https://doi.org/10.1016/j.ccr.2009.05.019.

12. A.R. Millward and O.M. Yaghi, J. Am. Chem. Soc., 127, 17998 (2005); https://doi.org/10.1021/ja0570032.
13. K. Schlichte, T. Kratzke and S. Kaskel, Micropor. Mesopor. Mater., 73, 81 (2004); https://doi.org/10.1016/j.micromeso.2003.12.027.

14. N.A. Khan, Z. Hasan and S.H. Jhung, J. Hazard. Mater, 244-245, 444 (2013); https://doi.org/10.1016/j.jhazmat.2012.11.011.

15. J. Della Rocca, D. Liu and W. Lin, Acc. Chem. Res., 44, 957 (2011); https://doi.org/10.1021/ar200028a.

16. A. Kondo, S. Takanashi and K. Maeda, J. Colloid Interface Sci., 384, 110 (2012); https://doi.org/10.1016/j.jcis.2012.06.040.

17. L. Qin, Y. Zhou, D. Li, L. Zhang, Z. Zhao, Z. Zuhra and C. Mu, Ind. Eng. Chem. Res., 55, 7249 (2016); https://doi.org/10.1021/acs.iecr.6b01001.

18. N.E. Tari, A. Tadjarodi, J. Tamnanloo and S. Fatemi, J. $\mathrm{CO}_{2}$ Util., 14, 126 (2016);

https://doi.org/10.1016/j.jcou.2016.04.008.

19. S. Badamali, A. Sakthivel and P. Selvam, Catal. Today, 63, 291 (2000); https://doi.org/10.1016/S0920-5861(00)00471-5.

20. P. Chowdhury, C. Bikkina, D. Meister, F. Dreisbach and S. Gumma, Micropor. Mesopor. Mater, 117, 406 (2009); https://doi.org/10.1016/j.micromeso.2008.07.029.

21. R.S. Kumar, S.S. Kumar and M.A. Kulandainathan, Micropor. Mesopor. Mater, 168, 57 (2013); https://doi.org/10.1016/j.micromeso.2012.09.028.

22. X. Yan, X. Hu and S. Komarneni, RSC Adv., 4, 57501 (2014); https://doi.org/10.1039/C4RA09626F.

23. Z.-Q. Li, A. Wang, C.-Y. Guo, Y.-F. Tai and L.-G. Qiu, Dalton Trans., 42, 13948 (2013); https://doi.org/10.1039/c3dt50845e.

24. I. Ardelean and S. Cora, J. Mater. Sci. Mater. Electron., 19, 584 (2008); https://doi.org/10.1007/s10854-007-9393-3.

25. S. Wu, K. Song, J. Guan and Q. Kan, Bull. Mater. Sci., 34, 979 (2011); https://doi.org/10.1007/s12034-011-0225-y.

26. Y. Feng, H. Jiang, S. Li, J. Wang, X. Jing, Y. Wang and M. Chen, Colloids Surf. A Physicochem. Eng. Asp., 431, 87 (2013); https://doi.org/10.1016/j.colsurfa.2013.04.032.

27. A.M.B. Furtado, J. Liu, Y. Wang and M.D. LeVan, J. Mater. Chem., 21, 6698 (2011); https://doi.org/10.1039/c1jm10451a.

28. C.-M. Wu, M. Rathi, S.P. Ahrenkiel, R.T. Koodali and Z. Wang, Chem. Commun., 49, 1223 (2013); https://doi.org/10.1039/c2cc38366g

29. Y. Xiong, F. Ye, C. Zhang, S. Shen, L. Su and S. Zhao, RSC Adv., 5, 5164 (2015); https://doi.org/10.1039/C4RA12468E.

30. R. Dod, G. Banerjee and S. Saini, Biotechnol. Bioprocess Eng., 17, 862 (2012);

https://doi.org/10.1007/s12257-011-0614-5.

31. J. Hu, W. Dai and X. Yan, Desalination Water Treat., 57, 4081 (2016); https://doi.org/10.1080/19443994.2014.988654.

32. X. Liu, J. Luo, Y. Zhu, Y. Yang and S. Yang, J. Alloys Compd., 648, 986 (2015); https://doi.org/10.1016/j.jallcom.2015.07.065.

33. L. Li, X.L. Liu, H.Y. Geng, B. Hu, G.W. Song and Z.S. Xu, J. Mater. Chem. A Mater. Energy Sustain., 1, 10292 (2013);

https://doi.org/10.1039/c3ta11478c. 